\title{
Introduction to Managing the Dynamics of Platforms and Ecosystems Minitrack
}

\author{
Jukka Huhtamäki \\ Tampere University \\ jukka.huhtamaki@.tuni.fi
}

\author{
Martha G. Russell \\ Stanford University \\ martha.russell@stanford.edu
}

\author{
Hannes Rothe \\ Freie Universität Berlin \\ hannes.rothe@,fu-berlin.de
}

\section{Introduction}

It is now well understood that to survive and compete in the information-driven, globally connected 21 st Century, organizations must acknowledge the speed and resilience of platforms and ecosystems. With the rapid emergence and proliferation of cloud services, artificial intelligence, and 5G, new human-machine relationships are emerging. These hybrid relationships introduce new opportunities and challenges creating and managing platforms and ecosystems. The field now needs taxonomies to describe generalizable concepts, longitudinal perspectives to discover evolutionary patterns, and analyses of dynamics to indicate strategic pathways to action. This minitrack continues to respond to the evolution of insights needed to manage the dynamics of platforms and ecosystems.

\section{Historical perspective}

During the six years of this minitrack, platform and ecosystem research has matured, as it has been inspired by rapid changes in management practices and scholarship. Investigations have evolved from largescale data-driven explorations and case studies in 2016 to 2021's taxonomic analyses, longitudinal perspectives, and automated computation. From the start, and into 2021, scholarly exploration has been inspired by interdisciplinary sociotechnical inquiry founded on information systems, business strategy, marketing, operations, computational science, social sciences, and policy sciences. Initially inspired by the availability of large digital datasets, evolving through differentiation of platforms and ecosystems to the integration reflected in platform ecosystems, enhanced by the recognition of human relationships and data exchanges as the basic infrastructure for continuously evolving ecosystems, this 2021 minitrack represents an evolution of inquiry situated at HICSS.

The initial minitrack in 2016, "Introduction to Analytics and Decision Support for Ecosystems," brought together researchers and practitioners to explore and understand ecosystems through data analytics for decision support. Papers focused on empirical studies using institutional data to reveal the dynamics of IT spending [1], large-scale social media data to reflect contagion in an interbank system [2], as well as on data gathered from social media to reveal board interlocks in game industry [3], fanbase influence in crowd funding [4], and network effects of international innovation ecosystems [5]. Questions arose about the application to management activities of insights from data analyses and case studies. The emergence of platforms was recognized in 2016, and the 2017 Call for Papers expanded the ecosystem theme to invite investigation of platforms and ecosystems for management activities such as designing, planning, implementing, decision making, and evaluation.

To better understand and support management in hyper-connected economies, the 2017 minitrack on "Managing Platforms and Ecosystems" differentiated ecosystems as complex socio-economic and technical systems of relationships characterized by human networks that generate productive output on a sustainable basis and platforms as conceptual or technological constructs to structure relationships and provide context and value creation in an ecosystem.

Papers in 2017 placed innovation ecosystems in the context of collaboration and co-creation of value [6], service system boundaries [7], and start-up industry [8], and provided computational tools for enhanced literature review [9]. Papers also addressed platform dynamics from a firm theory [10], transactional costs [11], structural holes in network positions [12], and business model taxonomy [13]. Discussions at the 50th HICSS Conference highlighted the need for scholarly exploration of concepts, theories, tools, and practices to inform the growing interest in platforms, platform economy and platform businesses.

In 2018, papers in the "Managing Platforms and Ecosystems" minitrack applied data analytical methods to explore network development in a university-industry program [14], business models in an emerging Fintech sector [15], and value co-creation in the Internet of 
Things [16]. They examined the impact of social media on networks of hype [17] and reputation in a restaurant ecosystem [18]. The implications of business strategy were explored from perspectives of multi-sided platforms [19], complementors [20], and data governance [21]. Managers and policy analysts asked for a deeper understanding of concepts that would aid in making decisions and orchestrating cooperation.

Case studies using data-driven analyses and indepth interviews responded to this need in the 2019 minitrack, "Managing Platforms and Ecosystems." With investigative lenses turned toward specific industries, papers explored the emergence of dynamic capabilities in the Internet of Things [22], the robotics sector [23], microservices [24], the fintech sector [25], and the automotive industry [26]. Management issues brought about by rapidly advancing technologies were addressed in papers on the alignment of information technologies with business strategies [27], shifting to the cloud [28], blockchain value creation [29], data governance decisions [30], and crowdworking [31]. The identification of success, failures, and unintended consequences prompted an expressed desire for deeper understanding of the management dynamics.

Then in 2020, the dynamic aspects of platforms and ecosystems gave focus to the "Managing the Dynamics of Platforms and Ecosystems" minitrack, exploring how platforms and ecosystems change, evolve, and adapt to technological, social, economic and political changes. Some of these papers took a data-centric view_offering an epistemological framework to support the coordinated use of multiple datasets in a data-driven ecosystem analysis [32], proposing a method for measuring the heterogeneity of startups' digital infrastructure [33], and identifying four archetypes of data marketplaces [34]. Strategies for organizing on and for platform ecosystems were investigated from the perspectives of organizational routines [35] and the balance of cooperation and competition [36].

Conference discussions at the 53rd HICSS Conference revealed a continued interest in sophisticated data acquisition and analysis techniques, as well as the importance of developing a shared language that could be used across multiple disciplinary perspectives. Across a variety of disciplines and sectors, we have continued to champion explorations in the management dynamics of platforms and ecosystems through both qualitative and quantitative methods identification of key concepts, definition and comparison of models, and development of insights to inform management decisions. In this 2021 minitrack, we invited contributions that would contribute to deepening this discovery by focusing on the dynamic aspects of the management of platforms and ecosystems.

\section{The 2021 minitrack}

We were delighted to receive nineteen (19) papers from authors in Europe, North America, Asia, and Australia. With the support of 47 outstanding reviewers, we accepted nine (9) papers for this minitrack. We thank the reviewers for their constructive and valuable comments, which inspired all the authors, as well as the organizers. Three major themes emerge from the accepted papers. First, indicating maturation of the socio-technical inquiry of platforms and ecosystems, three papers develop a taxonomy to enrich and clarify language for platforms and ecosystems. The second set of papers introduce data-driven insights on the evolution and mechanisms of platforms and ecosystems. Third, three teams provide insights on strategic pathways to action in managing and making decisions on emerging end ever-evolving ecosystems.

\subsection{Taxonomies: language for platforms and ecosystems}

The track accepted three papers that contributed taxonomies that introduce new vocabulary and syntax to be used that describe, discuss, and model platforms and ecosystems. Staub et al. [37] present a taxonomy for digital platforms considering their business models. Wulfert et al. [38] develop a taxonomy for multi-sided markets. Gelhaar et al. [39] present a taxonomy for data ecosystems. Each taxonomy represents an important stepping stone for the development of a coherent ontology for platforms and ecosystems. In established fields such as Physics (PhySH), Biology (MeSH), or Computer Science (CSO), history has shown that a common language guides, accelerates and helps accumulate knowledge contributions across studies. A clear language is important for studying platforms and ecosystems, particularly for the comparison of concepts across domains but also for exploration of these phenomena and their dynamics over time.

\subsection{Pathways to action}

Literature has rarely turned towards a longitudinal perspective on platforms and ecosystems, leaving scholars and practitioners with limited understanding for pathways to action as ecosystems and platforms emerge and evolve. The track accepted three papers that engage in a deep and comparative analysis of these dynamics through qualitative case studies. Piller et al. [40] explain how incumbents manage tensions that arise from transitioning an established business model to platform-based. Complementary, Hermes et al. [41] looks into incumbents transitioning to digital platforms 
and uncovers multiple transition strategies. Stegemann and Gersch [42] reveal interoperability challenges as incumbents face regulatory changes in the healthcare industry.

Another three papers present data-driven approaches to analyze pathways to action. Basole [43] presents a framework to map and study dynamics in artificial intelligence ecosystems that builds upon large data sets. Following a design science research approach, Betz and Jung [44] introduce a service configuration model that considers both the actor and the network level. Finally, Croitor et al. [45] investigate the effects of control mechanisms on complementors' behavioral intentions in platform ecosystems with survey data and a structural equation model.

\section{Invitation to inquiry}

Despite the contributions presented on the minitrack throughout the years, the dynamics of platforms and ecosystems remain understudied. Further, we lack the language to communicate on these dynamics and practices to manage them. Going forward into 2022 and beyond, we invite the authors, readers, and the other members of the minitrack community to continue the exploration of the mechanisms driving the dynamics, analytical methods to investigate the dynamics, language to discuss the dynamics, and management practices to reap the benefits of the dynamics.

\section{References}

[1] V. Krotov, "Using Skewness and Kurtosis Coefficients of Industry Samples of IT Managerial Control Ratios for Analyzing Competitive Dynamics in Relation to IT Spending", Proceedings of the 49th Hawaii International Conference on System Sciences, pp. 4525-4534

[2] X. Cheng, S. Liao, H. Zhao, Z. Hua, X. Sun, and Y. Xu, "A Study of Financial Contagion in Interbank System", Proceedings of the 49th Hawaii International Conference on System Sciences, pp. 4485-4494

[3] A. Suominen, N. Rilla, J. Oksanen, and K. Still, "Insights from Social Network Analysis -- Case Board Interlocks in Finnish Game Industry", Proceedings of the 49th Hawaii International Conference on System Sciences, pp. 4515-4524

[4] J. Jussila, K. Menon, R. Mukkamala, L. Lasrado, A. Hussain, R. Vatrapu, H. Kärkkäinen, and J. Huhtamäki, "Crowdfunding in the Development of Social Media Fanbase -- Case Study of Two Competing Ecosystems", Proceedings of the 49th Hawaii International Conference on System Sciences, pp. 44954504

[5] J. Huhtamäki, and N. Rubens, "Exploring Innovation Ecosystems as Networks: Four European Cases", Proceedings of the 49th Hawaii International Conference on System Sciences, pp. 4504-4513
[6] N. Smorodinskaya, M.G. Russell, D. Katukov, and K. Still, "Innovation Ecosystems vs. Innovation Systems in Terms of Collaboration and Co-creation of Value", Proceedings of the 50th Hawaii International Conference on System Sciences, pp. 5245-5254

[7] H. Rothe, and F. Steier, "Shaping the Boundaries of a Service Ecosystem: The Case of Udacity", Proceedings of the 50th Hawaii International Conference on System Sciences, pp. 5255-5264

[8] T-F. Kummer, and F. von Briel, "Explaining Digital Ecosystem Evolution: The Revelatory Case of a Digital Platform Start-up in the 3D Printing Industry", Proceedings of the 50th Hawaii International Conference on System Sciences.

[9] A. Hajikhani, "Emergence and Dissemination of Ecosystem Concept in Innovation Studies: A Systematic Literature Review Study", Proceedings of the 50th Hawaii International Conference on System Sciences, pp. 5227-5236

[10] D. Kim, "Value-Creation Dynamics in Platform Ecosystem: A Firm Theory Lens", Proceedings of the 50th Hawaii International Conference on System Sciences, pp. 5295-5304

[11] D. Dellermann, and F. Reck, "The Antecedents of Transaction Costs in Digital Ecosystems: A Configurational View on the Interplay of App Architecture and Platform Governance", Proceedings of the 50th Hawaii International Conference on System Sciences, pp. 5265-5274

[12] G. van de Kaa, "Explaining standard dominance: The effect of influential network positions and structural holes", Proceedings of the 50th Hawaii International Conference on System Sciences, pp. 5237-5244

[13] K. Täuscher, and S.M. Laudien, "Uncovering the Nature of Platform-based Business Models: An Empirical Taxonomy", Proceedings of the 50th Hawaii International Conference on System Sciences, pp. 52855294

[14] A. Hajikhani, M.G. Russell, K. Alexanyan, E. Young, and J. Wilmot, "University-Industry Programs as Platforms: A Case Study of Multi-Disciplinary Collaborative Network Development", Proceedings of the 51st Hawaii International Conference on System Sciences, pp. 49945003

[15] J. Schmidt, P. Drews, and I. Schirmer, "Charting the Emerging Financial Services Ecosystem of Fintechs and Banks: Six Types of Data-Driven Business Models in the Fintech Sector", Proceedings of the 51st Hawaii International Conference on System Sciences, pp. 50045013

[16] H. Ikävalko, P. Turkama, and A. Smedlund, "Enabling the Mapping of Internet of Things Ecosystem Business Models Through Roles and Activities in Value Cocreation", Proceedings of the 51st Hawaii International Conference on System Sciences, pp. 4954-4963

[17] R.C. Basole, "Visualizing Ecosystems of Hype", Proceedings of the 51st Hawaii International Conference on System Sciences, pp. 4964-4973

[18] Y. Zhang, and J. Zhang, "Could Nearby Pokéstops Improve Restaurants' Online Reputation?”, Proceedings 
of the 51st Hawaii International Conference on System Sciences, pp. 4984-4993

[19] K. Staykova, and J. Damsgaard, "Introducing Platform Interactions Model for Studying Multi-Sided Platforms", Proceedings of the 51st Hawaii International Conference on System Sciences, pp. 5024-5033

[20] S. Lee, S.J. Bae, M. Rhee, and M. Park, "Complementorside Ecology and its Implications on Platform Strategy", Proceedings of the 51st Hawaii International Conference on System Sciences, pp. 4974-4983

[21] S.U. Lee, L. Zhu, and R. Jeffery, "Designing Data Governance in Platform Ecosystems", Proceedings of the 51st Hawaii International Conference on System Sciences, pp. 5014-5023

[22] M. Dunaway Virginia, Y.W. Sullivan, and S. Fosso Wamba, "Building Dynamic Capabilities with the Internet of Things", Proceedings of the 51st Hawaii International Conference on System Sciences, pp. 59095918

[23] D. Kim, "Understanding the Robot Ecosystem: Don't lose sight of either the trees or the forest", Proceedings of the 52nd Hawaii International Conference on System Sciences, pp. 6321-6330

[24] R.C. Basole, "Visualizing Interfirm Collaboration in the Microservices Ecosystem", Proceedings of the 52nd Hawaii International Conference on System Sciences, pp. 6339-6346

[25] K. Still, I. Lähteenmäki, and M. Seppänen, "Innovation Relationships in the Emergence of Fintech Ecosystems", Proceedings of the 52nd Hawaii International Conference on System Sciences, pp. 6367-6376

[26] A. Hjalmarsson Jordanius, G. Juell-Skielse, and A. Kailas, "Digital Innovation and Incubators: A Comparative Interview Study from the Perspective of the Automotive Industry", Proceedings of the 52nd Hawaii International Conference on System Sciences, pp. 60016010

[27] M. Zhang, H. Chen, K. Lyytinen, and X. Li, “A Coevolutionary Perspective on Business and IT Alignment: A Review and Research Agenda", Proceedings of the 52nd Hawaii International Conference on System Sciences, pp. 6229-6238

[28] M. Schreieck, M. Wiesche, T. Kude, and H. Krcmar, "Shifting to the Cloud - How SAP's Partners Cope with the Change", Proceedings of the 52st Hawaii International Conference on System Sciences, pp. 60846093

[29] I. Bauer, L. Zavolokina, F. Leisibach, and G. Schwabe, "Exploring Blockchain Value Creation: The Case of the Car Ecosystem", Proceedings of the 52nd Hawaii International Conference on System Sciences, pp. 6865-6874

[30] S.U. Lee, L. Zhu, and R. Jeffery, "Data Governance Decisions for Platform Ecosystems", Proceedings of the 52nd Hawaii International Conference on System Sciences, pp. 6377-6386

[31] V. Mrass, and C. Peters, "Managing Work Systems for Complex Work via Crowdworking Platforms - How to Orchestrate the Interplay of Crowds", Proceedings of the 52nd Hawaii International Conference on System Sciences, pp. 6347-6356
[32] R.C. Basole, "Understanding Ecosystem Data", Proceedings of the 53rd Hawaii International Conference on System Sciences, pp. 5718-5727

[33] M. Schulte-Althoff, K. Schewina, G.M. Lee, and D. Fürstenau, "On the Heterogeneity of Digital Infrastructure in Entrepreneurial Ecosystems", Proceedings of the 53rd Hawaii International Conference on System Sciences, pp. 5728-5737

[34] M. Fruhwirth, M. Rachinger, and E. Prlja, "Discovering Business Models of Data Marketplaces", Proceedings of the 53rd Hawaii International Conference on System Sciences, pp. 5738-5747

[35] S. Seidel, T. Grisold, and N. Berente, "Modular Change in Platform Ecosystems and Routine Mirroring in Organizations", Proceedings of the 53rd Hawaii International Conference on System Sciences, pp. 57485757

[36] D. Yoo, J. Roh, S. Cho, and M.G. Yang, "Coopetition Balance and Coopetition Capability in Platform Ecosystems: Complementors' Perspective", Proceedings of the 53rd Hawaii International Conference on System Sciences, pp. 5758-5767

[37] N. Staub, K. Haki, S. Aier, and R. Winter, "Taxonomy of Digital Platforms: A Business Model Perspective", Hawaii International Conference on System Sciences 2021, pp. 1-10.

[38] T. Wulfert, S. Seufert, and C. Leyens, "Developing MultiSided Markets in Dynamic Electronic Commerce Ecosystems - Towards a Taxonomy of Digital Marketplaces", Hawaii International Conference on System Sciences 2021, pp. 1-10.

[39] J. Gelhaar, T. Groß, and B. Otto, “A Taxonomy for Data Ecosystems", Hawaii International Conference on System Sciences 2021, pp. 1-10.

[40] F. Piller, M. Van Dyck, D. Lüttgens, and K. Diener, "Positioning Strategies in Emerging Industrial Ecosystems for Industry 4.0", Hawaii International Conference on System Sciences 2021, pp. 1-10.

[41] S. Hermes, R. Guhl, M. Schreieck, J. Weking, and H. Krcmar, "Moving beyond the Build-or-Join Decision: A Multiple Case Study on Multi-Platform Strategies of Incumbent Firms", Hawaii International Conference on System Sciences 2021, pp. 1-10.

[42] L. Stegeman and M. Gersch. "The Emergence and Dynamics of Electronic Health Records - A Longitudinal Case Analysis of Multi-Sided Platforms from an Interoperability Perspective", Hawaii International Conference on System Sciences 2021, pp. 1-10.

[43] R.C. Basole, "Visualizing the Evolution of the AI Ecosystem", Hawaii International Conference on System Sciences 2021, pp. 1-10.

[44] C. Betz and R. Jung. "Conceptualizing and Analyzing Business Ecosystem Service Offerings", Hawaii International Conference on System Sciences 2021, pp. $1-10$.

[45] E. Croitor, D. Werner, and A. Benlian, "The Effects of Control Mechanisms on Complementors' Behavioral Intentions: An Empirical Study of Reward-Based Crowdfunding Platforms", Hawaii International Conference on System Sciences 2021, pp. 1-10 